\title{
Modelling the effect of curves on distance running performance
}

\author{
Paolo Taboga ${ }^{\text {Corresp., Equal first author, } 1 \text {, Rodger Kram }}{ }^{\text {Equal first author, } 2}$ \\ ${ }^{1}$ Kinesiology Department, California State University, Sacramento, United States \\ 2 Integrative Physiology Department, University of Colorado, Boulder, Colorado, United States \\ Corresponding Author: Paolo Taboga \\ Email address: paolo.taboga@csus.edu
}

Background Although straight ahead running appears to be faster, distance running races are predominately contested on tracks or roads that involve curves. How much faster could world records be run on straight courses?

Methods Here,we propose a model to explain the slower times observed for races involving curves compared to straight running. For a given running velocity, on a curve, the average axial leg force $\left(\mathrm{F}_{\mathrm{a}}\right)$ of a runner is increased due to the need to exert centripetal force. The increased $F_{a}$ presumably requires a greater rate of metabolic energy expenditure than straight running at the same velocity. We assumed that distance runners maintain a constant metabolic rate and thus slow down on curves accordingly. We combined published equations to estimate the change in the rate of gross metabolic energy expenditure as a function of $F_{a}$, where $F_{a}$ depends on curve radius and velocity, with an equation for the gross rate of oxygen uptake as a function of velocity. We compared performances between straight courses and courses with different curve radii and geometries.

Results The differences between our model predictions and the actual indoor world records, are between $0.45 \%$ in $3000 \mathrm{~m}$ and $1.78 \%$ in the $1500 \mathrm{~m}$ for males, and $0.59 \%$ in the $5000 \mathrm{~m}$ and $1.76 \%$ in the $3000 \mathrm{~m}$ for females. We estimate that a 2:01:39 marathon on a $400 \mathrm{~m}$ track, corresponds to 2:01:32 on a straight path and to 2:02:00 on a $200 \mathrm{~m}$ track.

Conclusion Our model predicts that compared to straight racecourses, the increased time due to curves, is notable for smaller curve radii and for faster velocities. But, for larger radii and slower speeds, the time increase is negligible and the general perception of the magnitude of the effects of curves on road racing performance is not supported by our calculations. 
1

2

3

4

5

6

7

8

9 Corresponding author:

10

11 Paolo Taboga

12 California State University, Sacramento

13 6000J Street

14 Sacramento, CA 95819

15 paolo.taboga@,csus.edu 


\section{Abstract}

17

18 Background Although straight ahead running appears to be faster, distance running races are predominately contested on tracks or roads that involve curves. How much faster could world records be run on straight courses?

21 Methods Here, we propose a model to explain the slower times observed for races involving curves compared to straight running. For a given running velocity, on a curve, the average axial leg force $\left(\overline{F_{a}}\right)$ of a runner is increased due to the need to exert centripetal force. The increased $\overline{F_{a}}$ presumably requires a greater rate of metabolic energy expenditure than straight running at the same velocity. We assumed that distance runners maintain a constant metabolic rate and thus slow down on curves accordingly. We combined published equations to estimate the change in the rate of gross metabolic energy expenditure as a function of $\overline{F_{a}}$, where $\overline{F_{a}}$ depends on curve radius and velocity, with an equation for the gross rate of oxygen uptake as a function of velocity. We compared performances between straight courses and courses with different curve radii and geometries.

Results The differences between our model predictions and the actual indoor world records, are between $0.45 \%$ in $3000 \mathrm{~m}$ and $1.78 \%$ in the $1500 \mathrm{~m}$ for males, and $0.59 \%$ in the $5000 \mathrm{~m}$ and $1.76 \%$ in the $3000 \mathrm{~m}$ for females. We estimate that a 2:01:39 marathon on a $400 \mathrm{~m}$ track, corresponds to $2: 01: 32$ on a straight path and to $2: 02: 00$ on a $200 \mathrm{~m}$ track.

Conclusion Our model predicts that compared to straight racecourses, the increased time due to curves, is notable for smaller curve radii and for faster velocities. But, for larger radii and slower speeds, the time increase is negligible and the general perception of the magnitude of the effects of curves on road racing performance is not supported by our calculations. 


\section{Introduction}

Although straight ahead running appears to be faster, distance running races are predominately contested on tracks or roads that involve curves. How much faster could world records be run on straight courses? Could the 2-hour marathon barrier be broken without pacers or drafting if the course was perfectly straight? Could women break the 4-minute mile barrier?

Previous analysis of curve running has focused on sprinting. Coherent explanations for slower human sprint performances on curves, based on physics and biomechanics, are supported by substantial empirical evidence. The requirement to exert centripetal force (Greene 1985), and more specifically the force generated by the inside leg (Chang and Kram 2007; Churchill et al. 2016), adequate friction/traction (Alexander 2002; Luo and Stefanyshyn 2011; Luo and Stefanyshyn 2012), and ankle inversion/eversion torques (Greene 1987; Luo and Stefanyshyn 2012) have all been implicated as explanations for reduced sprint velocity along curves. Quadrupedal (greyhound) sprint performance on curves is less explored and more controversial (Usherwood and Wilson 2005; Hayati et al. 2017). A sizable body of scientific research articles also exist regarding the mechanics and energetics of small radius turns executed by humans and other animals (e.g. Wilson et al. 2013) but such turns do not involve substantial centripetal forces.

Here, we focus on how curves affect the middle- and long-distance running performance of human athletes. Performances on standard indoor tracks $(200 \mathrm{~m} / \mathrm{lap}$ with curve radii of $17.2 \mathrm{~m}$ (IAAF 2008a)) are generally slower than on tracks with larger radii. For example, the National Collegiate Athletics Association (NCAA) equates a 4:03.07 mile on a standard $200 \mathrm{~m}$ indoor track to a 4:00.00 mile on an "oversized" track (i.e. > $300 \mathrm{~m} / \mathrm{lap}$ ) (Pederson et al. 2012) (NCAA, 2012). What are the physiological/biomechanical mechanisms responsible for this effect?

A fundamental physiological limit to distance running performance is the ability to generate adequate energy (i.e. ATP) from aerobic metabolism. Three physiological factors determine distance running performance: maximal aerobic capacity $\left(\mathrm{VO}_{2}\right.$ max $)$, the submaximal rate of oxygen uptake required to run at a specified velocity (aka "running economy") and the \% or fraction of the maximal aerobic capacity that can be sustained (Bassett and Howley 2000; Coyle 1995; Joyner and Coyle 2008; Ferretti et al. 2011). For example, an elite male marathon runner might have a $\mathrm{VO}_{2}$ max of $86 \mathrm{mlO}_{2} / \mathrm{kg} / \mathrm{min}$ and the physiology to sustain $85 \%$ of that $\mathrm{VO}_{2} \max$ $(71 \mathrm{ml} \mathrm{O} 2 / \mathrm{kg} / \mathrm{min}$ ) for more than 2 hours at a velocity of $5.55 \mathrm{~m} / \mathrm{s}$ in a straight line (Joyner 1991).

The rates of oxygen uptake or metabolic energy required to run straight-ahead at a specified velocity are proportional to the force applied to the ground (Arellano and Kram 2014; Kipp et al. 2018b; Kram and Taylor 1990). During distance running, the vertical ground reaction force (GRF) vs. time pattern resembles a half-sine wave with a peak magnitude of 2.5 to $4 \mathrm{x}$ body weight depending on velocity. During straight-line running, the vertical GRF averaged over a complete stride is equal to $1.0 \mathrm{x}$ body weight (BW). But, when a person runs along a curved path on a flat surface, they lean in towards the center of the curve and the required average force axial to the leg is greater than 1.0 BW due to the need to exert a centripetal force. The greater average axial leg force presumably requires a greater rate of metabolic energy expenditure than straight running. Centripetal force is equal to $\mathrm{mv}^{2} / \mathrm{r}$, where $\mathrm{m}$ is body mass, $\mathrm{v}$ is tangential velocity and $\mathrm{r}$ is the curve radius. Hamill et al. (1987) have measured GRF during distance running on curves equivalent to 
85

86

87

88

89

90

91

92

93

94

95

96

97

98

99

100

101

102

103

104

105

106

107

108

109

110

111

112

113

114

115

116

117

118

119

120

121

122

123

124

125

126

127

128

129

an outdoor $400 \mathrm{~m}$ track and for $\mathrm{v}=6.3 \mathrm{~m} / \mathrm{s}$ (corresponding to a mile time of $4: 15.00$ ) the peak centripetal GRF is $\sim 0.6 \mathrm{BW}$. Accordingly, an athlete must run slower on a curved path to maintain the same metabolic energy expenditure.

Overall, our objective was to combine physics and physiology to model the energetics of running on curved paths. From these energetic cost estimates, we then calculated race time differentials for various race distances and velocities. A few distance running races occur along straight paths (e.g. the Fifth Avenue Mile in New York City) but most involve at least one turn. We begin our analysis by modelling an out-and-back racecourse with a single $180^{\circ}$ turn. We then move to the much more common track races which are contested on standard $200 \mathrm{~m}$ indoor oval tracks (inner edge radius $=17.2 \mathrm{~m}$ ) and standard $400 \mathrm{~m}$ outdoor oval tracks (inner edge radius $=36.5 \mathrm{~m}$ ). According to the rules of the governing body for athletics, the IAAF (IAAF 2008a; IAAF 2008b), both indoor and outdoor tracks must be measured $0.3 \mathrm{~m}$ from the raised curb positioned at the inner edge of lane 1. The added $0.3 \mathrm{~m}$ takes in account the theoretical line of running (IAAF 2008b) of athletes who will run on curves with actual radii of $17.5 \mathrm{~m}$ (IAAF 2008a) and $36.8 \mathrm{~m}$ (IAAF 2008b) on indoor and outdoor tracks respectively. We then consider races longer than $10000 \mathrm{~m}$ which are predominately conducted on road surfaces. Road-racing courses typically involve multiple turns of different radii and we demonstrate how we can apply our model to any course configuration. Finally, urban races often involve negotiating city blocks comprising 90 degree angles. According to the IAAF, road racing courses must be measured $0.3 \mathrm{~m}$ from the curb (IAAF) which equates to $0.3 \mathrm{~m}$ radius. In the appendix, we consider the special case of running races on rectangular city blocks.

\section{Methods}

Gross metabolic energy expenditure as a function of body weight

Using a spring and harness system, Teunissen et al. (2007) quantified how simulated reduced gravity decreased the gross rate of metabolic energy expenditure during treadmill running. We utilized their data to calculate the fractional change in the rate of gross metabolic energy expenditure $f$ as a function of the average axial leg force $\left(\overline{F_{a}}\right)$

$$
f=0.6234 \overline{F_{a}}+0.3766
$$

where $\overline{F_{a}}$ is expressed as multiples of body weight (BW) and is calculated over an entire stride cycle (from touch down of one leg to the next touch down of the same leg). While Teunissen et al. (2007) only measured metabolic energy expenditure in normal and simulated reduced gravity $\left(\overline{F_{a}}\right.$ $\leq 1 \mathrm{BW}$ ), we assume that the slope in Eq. 1 extends to $\overline{F_{a}}>1 \mathrm{BW}$. According to equation 1 , when a person is running in a straight line ( $F_{a}=1 \mathrm{BW}$ ), $f=1$ (i.e. no change). If $\overline{F_{a}}=1.25$ (a $25 \%$ increase in average axial force), $f=1.16$ (a 16\% increase in gross metabolic energy expenditure). Note that we calculated Eq. 1 based on the data of Teunissen et al. (2007) but to calculate the gross rate of metabolic energy expenditure, we added Teunissen et al.'s standing metabolic rate value of $1.87 \mathrm{~W} / \mathrm{kg}$ to the net values reported in their tables. Further, we forced the regression to have an exact value of $f=1$ when $\overline{F_{a}}=1$.

Peer) reviewing PDF | (2019:07:39890:1:2:NEW 7 Nov 2019) 
130

131

132

133

134

135

136

137

138

139

140

141

142

143

144

145

146

147

148

149

150

151

152

153

154

155

156

157

158

159

160

161

162

163

164

165

166

167

168

169

170

\section{Axial leg force as a function of velocity and curve radius}

A person with a body mass $m(\mathrm{~kg})$, running with a tangential velocity $v(\mathrm{~m} / \mathrm{s})$ on a curve of radius

$r(\mathrm{~m})$ is subject to two forces in the frontal plane (Greene 1985): $\overline{F_{v}}$ the average force in the vertical direction due to gravity,

$$
\overline{F_{v}}=m g
$$

where $g$ is gravitational acceleration, and $\overline{F_{c}}$ the average centripetal force,

$$
\overline{F_{c}}=m v^{2} / r
$$

The vector sum of $F_{v}$ and $F_{c}$ is the average axial leg force:

$$
\overline{F_{a}}=\sqrt{{\overline{F_{v}}}^{2}+{\overline{F_{c}}}^{2}}
$$

where $\overline{F_{a}}$ is measured in newtons $(\mathrm{N})$. Dividing Eq. 4 by the body weight of the runner (1 $B W=m g$ ) and combining it with Eq. 2 and 3, the average axial force $\overline{F_{a}}$ can be calculated in multiples of body weight:

$$
\overline{F_{a}}=\sqrt{1+\frac{v^{4}}{(g r)^{2}}}
$$

Gross rate of metabolic energy expenditure during curve running

By inserting Eq. 5 into Eq. 1, it is possible to calculate the fractional increase, $f$, in the gross rate of metabolic energy expenditure for a runner with a tangential velocity $v$, on a curve of radius $r$ compared to running straight-ahead at the same velocity:

$$
f=0.6234 \sqrt{1+\frac{v^{4}}{(g r)^{2}}}+0.3766 \text { (Eq. 6) }
$$

As $r \rightarrow \infty$ (straight running), $\overline{F_{a}} \rightarrow 1$ in Eq. 5 (Fig. 1a) and therefore Eq. 6 reduces to $f \rightarrow 1$ (Fig. 1c) irrespective of running velocity $v$. At slower velocities, as $v \rightarrow 0, \overline{F_{a}} \rightarrow 1$ in Eq. 5 (Fig. 1b) and therefore Eq. 6 reduces to $f \rightarrow 1$ (Fig. 1d) irrespective of curve radius $r$.

\section{Running velocity on straight and curved paths}

The following equation, derived by Kipp et al. (2019), expresses the relationship between gross rate of oxygen uptake $\left(\dot{V} O_{2 s}\right)$ and overground running velocity $\left(v_{s}\right)$ on a straight path:

$$
\dot{V} O_{2 s}=0.02724 v_{s}^{3}+1.7321 v_{s}^{2}-0.4538 v_{s}+18.91 \quad \text { (Eq. 7) }
$$


171

172

173

174

175

176

177

178

179

180

181

182

183

184

185

186

187

188

189

190

191

192

193

194

195

196

197

198

199

200

201

202

203

204

205

206

207

208

209

210

211

212 where $\dot{V} O_{2 s}$ is measured in $\mathrm{mlO}_{2} / \mathrm{min} / \mathrm{kg}$. The cubic term in Eq. 7 takes into account air resistance (Pugh 1970). The Kipp et al. (2019) equation is based on submaximal (below lactate threshold, LT), steady state measurements of oxidative metabolic rates. Beyond the lactate threshold, indirect calorimetry calculations (derived from oxygen uptake and carbon dioxide production rates) do not represent all of the metabolic energy required. However, we believe that extrapolating to faster speeds (beyond LT) provides a reasonable measure of the total metabolic energy required even though in reality that energy is supplied by both oxidative and non-oxidative metabolism.

To calculate the gross rate of oxygen uptake of a person running on a curve $\left(\dot{V} O_{2 c}\right)$ with a tangential velocity along the curve $v_{c}$, we can combine Eq. 6 and 7:

$$
\dot{V} O_{2 c}=\left(0.6234 \sqrt{1+\frac{v_{c}^{4}}{(g r)^{2}}}+0.3766\right)\left(0.02724 v_{c}^{3}+1.7321 v_{c}^{2}-0.4538 v_{c}+18.911\right)(\text { Eq. } 8)
$$

where $\dot{V} O_{2 c}$ is measured in $\mathrm{mlO}_{2} / \mathrm{min} / \mathrm{kg}$. Note: we and others prefer to express running economy in units of energy or power (e.g. W/kg or kcals/min $/ \mathrm{kg}$ ) (Beck et al. 2018; Fletcher et al. 2009; Kipp et al. 2018a; Shaw et al. 2014) to account for differences in substrate utilization and therefore, in the amount of energy liberated per liter of oxygen uptake. However, Pugh (1970) used oxygen uptake rates. For our purpose here, assuming equivalence between rates of metabolic energy utilization and oxygen uptake incurs an insignificant error because we are only considering small changes in metabolic rate between curve and straight-line running.

A runner maintaining a constant velocity on both straight and curved portions $\left(v_{s}=v_{c}\right)$, would therefore alternate their gross rates of metabolic energy expenditure according to Eq. 7 and 8 respectively, where $\dot{V} O_{2 c}>\dot{V} O_{2 s}$. A runner performing at the maximal sustainable percentage of their aerobic capacity on the straight portion of a race cannot sustain an equal tangential velocity on the curve, since this would increase their rate of metabolic energy expenditure. Rather, in order to maintain the same metabolic energy expenditure throughout the race, running velocity on the curve must be reduced $\left(v_{c}<v_{s}\right)$ so that $\dot{V} O_{2 c}=\dot{V} O_{2 s}$.

To calculate the running velocity on the curve $\left(v_{c}\right)$ for a given velocity on the straight $\left(v_{s}\right)$, we used numerical approximation methods (see Appendix for algorithm 1). To calculate the increased time during a single gradual $180^{\circ}$ turn in an out-and-back race, we first used Eq. 7 to calculate the required $\dot{V} O_{2 s}$ for a straight racecourse. We then calculated the running velocity $v_{c}$ on the curved portion according to Eq. 8 given the same metabolic energy expenditure $\left(\dot{V} O_{2 c}=\dot{V} O_{2 s}\right)$ for a range of radii from $0.3 \mathrm{~m}$ (minimum radius according to IAAF rules (IAAF)) up to $36.8 \mathrm{~m}$ (outdoor track (IAAF 2008b)). The increased time during the curved portion is calculated as:

$$
\Delta t_{180^{\circ}}=\frac{d_{c}}{v_{c}}-\frac{d_{c}}{v_{s}}
$$

where $d_{c}$ is the distance run in the $180^{\circ}$ turn, corresponding to $\pi r$. 
213

214

215

216

217

218

219

220

221

222

223

224

225

226

227

228

229

230

231

232

233

234

235

236

237

238

239

240

241

242

243

244

245

246

247

248

249

250

251

252

253

In order to calculate the time difference between a straight race course $\left(t_{\text {straight }}\right)$ and the same racing distance on indoor or outdoor tracks, we used the same approach described above, i.e.: we assumed that an athlete maintains the same metabolic energy expenditure on the straight and on the curved portion of the track $\left(\dot{V} O_{2 c}=\dot{V} O_{2 s}\right)$, with the curve radii set at $17.5 \mathrm{~m}$ for indoor track (IAAF 2008a) and $36.8 \mathrm{~m}$ for the outdoor track (IAAF 2008b). The total time $\left(t_{\text {track }}\right)$ on the track is then calculated as:

$$
t_{\text {track }}=\frac{d_{s}}{v_{s}}+\frac{d_{c}}{v_{c}}
$$

where $d_{s}$ and $d_{c}$ are the total distances run on the straight and curved portions of the track, respectively, and the total racing distance is $d_{t o t}=d_{s}+d_{c}$.

Vice-versa, when a certain time $t_{\text {track }}$ on the track is known, assuming that $\dot{V} O_{2 c}=\dot{V} O_{2 s}$, it is possible to calculate the respective velocities on the straight and curved paths, $v_{s}$ and $v_{c}$, that satisfy Eq. 10 (see Appendix for algorithm 2). The respective time on a straight racecourse would then be:

$$
t_{\text {straight }}=\frac{d_{\text {tot }}}{v_{s}}
$$

The same procedure can be used to convert times between tracks with different curve radii and/or sizes: for example between indoor $\left(r_{\text {indoor }}=17.5 \mathrm{~m}\right.$, distance of one lap $\left.d_{\text {lap,indoor }}=200 \mathrm{~m}\right) \mathrm{vs}$. outdoor tracks ( $r_{\text {outdoor }}=36.8 \mathrm{~m}, d_{\text {lap,outdoor }}=400 \mathrm{~m}$ ).

For a given racing distance, it is possible to calculate the time difference $\Delta t$ as follows:

$$
\Delta t=t_{\text {indoor track }}-t_{\text {outdoor track }}(\text { Eq. 12) }
$$

to compare indoor vs. outdoor tracks,

and:

$$
\Delta t=t_{\text {straight }}-t_{\text {outdoor track }}(\text { Eq. 13) }
$$

to compare straight racecourses vs. outdoor tracks.

Given that $r_{\text {indoor }}<r_{\text {outdoor }}, \Delta t>0$ in Eq. 12 represents the increased amount of time for running on an indoor track while keeping the same rate of oxygen uptake maintained on the outdoor track. On the other hand, given that $r_{\text {straight }} \rightarrow \infty, \Delta t<0$ in Eq. 13 represents the increased amount of time for running on a straight racecourse while keeping the same rate of oxygen uptake maintained on the outdoor track. We used the outdoor $400 \mathrm{~m}$ track as a reference because the majority of racing distances $(1500 \mathrm{~m}, 3000 \mathrm{~m}, 5000 \mathrm{~m}$ and $10000 \mathrm{~m})$ are commonly run on outdoor 
254

255

256

257

258

259

260

261

262

263

264

265

266

267

268

269

270

271

272

273

274

275

276

277

278

279

280

281

282

283

284

285

286

287

288

289

290

291

292

293

tracks, compared to indoor tracks $(1500 \mathrm{~m}, 3000 \mathrm{~m}$ and $5000 \mathrm{~m})$ and very few races are contested on straight racecourses.

We also determined the ideal geometry of an outdoor track, where we kept the track lap distance constant $\left(d_{\text {lap,outdoor }}=400 \mathrm{~m}\right.$ ) and changed curve radii from $r=6 \mathrm{~m}$, corresponding to an oval track with a total straight portion of $362.3 \mathrm{~m}$ and a total curved portion of $37.7 \mathrm{~m}$ per lap, to $r=63.66 \mathrm{~m}$, corresponding to a perfectly circular track with all $400 \mathrm{~m}$ run on the curved portion.

We selected the world record times $t_{W R}$ on a standard outdoor track for $1500 \mathrm{~m}, 3000 \mathrm{~m}, 5000 \mathrm{~m}$ and $10000 \mathrm{~m}$ as a reference and then calculated the total racing time $t(r)$ as a function of the different curve radii $r$ according to Eq. 10 . The time difference $\Delta t$ :

$$
\Delta t=t(r)-t_{W R}(\text { Eq. 14) }
$$

is the increased time $(\Delta t>0)$ or decreased time $(\Delta t<0)$ as a function of radius $r$ compared to the respective world record. The ideal track geometry corresponds to the curve radius that allows the biggest time savings.

More generally, these algorithms can be used to convert times between straight racecourses and the same distance run on a path with a series of curves with different radii:

$$
t_{\text {path }}=\frac{d_{s}}{v_{s}}+\sum \frac{d_{c, i}}{v_{c, i}}
$$

where $d_{c, i}$ is the distance ran on the $\mathrm{i}$-th curve, with a given radius $r_{i}$, and $v_{c, i}$ is the velocity on the i-th curve.

\section{Breaking 2 on a straight path}

Using Equation 15, we analyzed the racetrack in Monza, Italy used for the "Breaking 2" marathon exhibition (https://en.wikipedia.org/wiki/Breaking2). We divided the total lap distance, $d_{\text {lap,Monza }}$ $=2424.4 \mathrm{~m}$ (17.4 laps to run a full marathon: $42195 \mathrm{~m}$ ) into a straight portion $d_{s}=1907 \mathrm{~m}$ and 6 different curves (see Fig. 2, racetrack blueprints: personal communication, Brett Kirby, Ph.D.). We divided the "Curva parabolica" into three different portions in order to account for the nonconstant radius of this specific section. All other curves were assumed to have a fixed radius throughout each section. We then applied the same algorithm described in the previous paragraph: we calculated the running velocities on the straight and on each of the curved portions of the track assuming that Eliud Kipchoge maintained a constant $\dot{V} O_{2 s}=\dot{V} O_{2 c}$. We then converted the total time $t_{\text {Monza }}=7225 \mathrm{~s}$ ( 2 hours and 25 seconds) to the time $t_{\text {straight }}$ that Kipchoge might have run on a straight path with a length $d_{t o t}=42195 \mathrm{~m}$, while maintaining all the other factors (drafting, shoes, hydration etc.) adopted during the Breaking 2 attempt. 
294

295

296

297

298

299

300

301

302

303

304

305

306

307

308

309

310

311

312

313

314

315

316

317

318

319

320

321

322

323

324

325

326

327

328

329

330

331

332

\section{Results}

Increased time for a single $180^{\circ}$ turn

We report the increased time $\Delta t_{180^{\circ}}$ as a function of radius $r$ according to Eq. 9 for three different representative velocities $\left(v_{1}=7.3 \mathrm{~m} / \mathrm{s}\right.$, corresponding to Hicham el Guerrouj's $1500 \mathrm{~m}$ world record; $v_{2}=6 \mathrm{~m} / \mathrm{s}$, corresponding to the men's half marathon world record; and a recreational running velocity, $v_{3}=4 \mathrm{~m} / \mathrm{s}$ ) in Fig. 3. The radius $r$ influences both the distance run on the curve $d_{c}$ and the velocity on the curve $v_{c}$ in Eq. 9. As $r \rightarrow \infty, d_{c} \rightarrow \infty$, but given that $v_{c} \rightarrow v_{s}$ (Eq. 8), the increased time $\Delta t_{180^{\circ}} \rightarrow 0$. As $r$ decreases, $v_{c}<v_{s}$ and $\Delta t_{180^{\circ}}$ starts to increase up to a specific radius $\hat{r}$, different for each velocity. In particular $\hat{r}_{1}=2.7 \mathrm{~m}$ and $\Delta t_{180^{\circ}}=0.261 \mathrm{~s}$ for $v_{1} ; \hat{r}_{2}=1.9 \mathrm{~m}$ and $\Delta t_{180^{\circ}}=0.232 \mathrm{~s}$ for $v_{2} ; \hat{r}_{3}=0.8 \mathrm{~m}$ and $\Delta t_{180^{\circ}}=0.193 \mathrm{~s}$ for $v_{3} . \hat{r}$, therefore, represents the worst radius in terms of velocity reduction $\left(v_{c}<v_{s}\right)$ and non-trivial distance run on the curve $\left(d_{c}>0\right)$. As $r$ further decreases $(r<\hat{r}), d_{c} \rightarrow 0$, leading to an overall decrease in $\Delta t_{180^{\circ}}$.

\section{Outdoor tracks vs. indoor tracks vs. straight races}

We report the time difference $\Delta t$ a function of running velocity $v$ in Fig. 4 a $(1500 \mathrm{~m}, 5000 \mathrm{~m}$ and $10000 \mathrm{~m}$ ) and Fig. 4b (half marathon and marathon) respectively, the maximum velocity $v$ for each distance corresponds to the respective current men's world record. In both figures, $\Delta t>0$ represents the increased amount of time for running on an indoor track $(r=17.5 \mathrm{~m})$ compared to the outdoor track $(r=36.8 \mathrm{~m})$, while $\Delta t<0$ represents the decreased amount of time for running on a straight racecourse compared to an outdoor track. The increased or decreased amount of time compared to an outdoor track increases non-linearly with velocity $v$ and is inversely proportional to the curve radius $r$ (see Appendix for step-by-step algorithms). In addition, we selected four racing distances commonly contested on outdoor oval tracks $(1500 \mathrm{~m}, 3000 \mathrm{~m}, 5000 \mathrm{~m}$ and 10000 $\mathrm{m})$. Based on the actual outdoor $400 \mathrm{~m}$ track world records for both males and females, we calculated the respective time the same athlete would have run on an indoor track and on a straight racecourse, while keeping the same rate of oxygen uptake maintained on the outdoor track (Table 1). For comparison, we report the actual world record on the indoor track for $1500 \mathrm{~m}, 3000 \mathrm{~m}$ and $5000 \mathrm{~m}$ distances. $10000 \mathrm{~m}$ is not officially run on an indoor track (IAAF 2018).

According to our model, an athlete running a marathon in 2:01:39 (corresponding to the actual world record, $v=5.78 \mathrm{~m} / \mathrm{s}$ ) on an outdoor track, would run 2:01:32 on a straight path and 2:02:00 on an indoor track. According to our model, an athlete running a half marathon in 58:01 (corresponding to the actual world record, $v=6.06 \mathrm{~m} / \mathrm{s}$ ) on an outdoor track, could run 57:57 on a straight path and 58:13 on an indoor track (Fig. 4b).

Peer) reviewing PDF | (2019:07:39890:1:2:NEW 7 Nov 2019) 
333

334

335

336

337

338

339

340

341

342

343

344

345

346

347

348

349

350

351

352

353

354

355

356

357

358

\section{Ideal geometry of $400 \mathrm{~m}$ track}

For a track constrained to comprise a $400 \mathrm{~m}$ lap, we report the time difference $\Delta t$ a function of curve radius $r$ in Fig. 5 for $1500 \mathrm{~m}, 3000 \mathrm{~m}, 5000 \mathrm{~m}$, and $10000 \mathrm{~m}$ respectively. The plots intersect at $(r=36.8 \mathrm{~m}, \Delta t=0 \mathrm{~s})$, where $t(r)=t_{W R}$. For $r<36.8 \mathrm{~m}, \Delta t>0 \mathrm{~s}$, indicating that a reduction in curve radius, compared to standard outdoor tracks, is detrimental for performance. For example, when $r=6 \mathrm{~m}, \Delta t$ values range between $+1.18 \mathrm{~s}$ for $1500 \mathrm{~m}$ and $+7.14 \mathrm{~s}$ for $10000 \mathrm{~m}$. On the other hand, for $r>36.8 \mathrm{~m}, \Delta t<0 \mathrm{~s}$ for all distances, indicating that an increase in curve radius, compared to standard outdoor tracks, favors performance; in particular, at the maximum radius $(r=63.66 \mathrm{~m})$ $\Delta t$ equals $-0.15 \mathrm{~s}$ for $1500 \mathrm{~m},-0.31 \mathrm{~s}$ for $3000 \mathrm{~m},-0.48 \mathrm{~s}$ for $5000 \mathrm{~m}$ and $-0.86 \mathrm{~s}$ for $10000 \mathrm{~m}$

\section{Breaking 2 on a straight path}

We report the velocities $v_{c}$ on each of the curve portions and the velocity $v_{s}$ on the straight portions, calculated assuming that Kipchoge maintained a constant oxygen uptake $\left(\dot{V} O_{2 c}=\dot{V} O_{2 s}\right.$ ) in Table 2. Note that combining each velocity with the respective distance, the time for a full lap $(2424.4 \mathrm{~m})$ is $t_{\text {lap,Monza }}=415.1 \mathrm{~s}$, and the total time for a full marathon (17 full laps plus the remaining 0.4 laps, i.e. $980.2 \mathrm{~m}$ on the last straight portion) coincides with $t_{\text {Monza }}=7225 \mathrm{~s}$.

To calculate the time $t_{\text {straight }}$ that Kipchoge could have run on a straight marathon course, it is sufficient to divide the total distance by the velocity on the straight:

$$
t_{\text {straight }}=\frac{d}{v_{s}}=\frac{42195}{5.8414}=7223.48 s(\text { Eq. 16) }
$$

leading to an overall time difference of only $\Delta t=1.52 \mathrm{~s}$. 
359

360

361

362

363

364

365

366

367

368

369

370

371

372

373

374

375

376

377

378

379

380

381

382

383

384

385

386

387

388

389

390

391

392

393

394

395

396

397

398

399

400

401

402

403

\section{Discussion}

According to our model, the increased time $\Delta t_{180^{\circ}}$ for an out-and-back race course (i.e.: with a single $180^{\circ}$ turn) is less than $0.27 \mathrm{~s}$ even in the worst-case scenario (high velocity, $7.3 \mathrm{~m} / \mathrm{s}$, and small curve radius, $2.7 \mathrm{~m}$ ). Nevertheless, race organizers trying to keep $\Delta t_{180^{\circ}}$ to a minimum, should aim for the largest curve radius allowed by road widths, the presence of buildings/sidewalks, median strip etc..

IAAF rules (2018) require that, in order for a race course to be record-eligible, the start and finish points of any road race shall not be further apart than $50 \%$ of the total race distance (Rule 260.21), making the presence of at least one curve mandatory for all record-eligible courses. While having the largest possible radius is still a valid recommendation, on races measuring $5000 \mathrm{~m}$ and longer, athletes can maintain a lower velocity compared to the scenario described above $(6.6 \mathrm{~m} / \mathrm{s}$ being the average velocity for Bekele's $5000 \mathrm{~m}$ world record), and would therefore experience even lower values for $\Delta t_{180^{\circ}}$. In addition, $\Delta t_{180^{\circ}}$ becomes trivial in terms of percentage of the total race time especially in races like the half marathon or the marathon, while other factors, like change in elevation (Giovanelli et al. 2016; Hoogkamer et al. 2014), surface type (Kerdok et al. 2002), drafting (Hoogkamer et al. 2019) etc., have a much greater effect on running energetics and therefore on the overall time (Hoogkamer et al. 2016). For example, Hoogkamer et al. (2017) estimated that the maximum allowable downhill elevation drop $(42 \mathrm{~m})$ in a marathon could save 28 seconds, and a legal tailwind could save $\sim 3$ minutes. More economical running shoes should save roughly 3 minutes (Kipp et al. 2019).

Lacking empirical data from a controlled study, we can only evaluate the validity of our model by comparing our predictions to actual race performances. Starting with the outdoor $400 \mathrm{~m}$ track records, our model predicts faster indoor world records compared to the actual record times in all distances for both males (Table 1A) and females (Table 1B).

The differences between our model predictions and the actual indoor world records, based on the times run on $400 \mathrm{~m}$ outdoor tracks, are $3.75 \mathrm{~s}(1.78 \%)$ in the $1500,2.2 \mathrm{~s}(0.45 \%)$ in $3000 \mathrm{~m}$, and $8.82 \mathrm{~s}(1.14 \%) 5000 \mathrm{~m}$ for males (Table $1 \mathrm{~A})$, and $4.1 \mathrm{~s}(1.74 \%)$ in the 1500 , to $8.73 \mathrm{~s}(1.76 \%)$ in the $3000 \mathrm{~m}$ and $5.09(0.59 \%)$ in the $5000 \mathrm{~m}$ for females (Table 1B). It must be noted that multiple factors can contribute to these differences between predicted and actual times. Indoor races are typically run in winter, while outdoor races are run in spring/summer and athletes tend to reach peak fitness for outdoor races when major international competitions (Olympics, World Championship etc.) are held. Only the men's $5000 \mathrm{~m}$ indoor and outdoor records were run by the same athlete (Kenenisa Bekele) in the same year. All other indoor and outdoor records were run by the same athlete, but in different years, or by different athletes. Pacing and drafting play important roles when trying to run a world record time (Hoogkamer et al. 2019); it is likely more difficult for athletes on indoor tracks to negotiate the smaller curve radiuses while following or overtaking other competitors, compared to outdoor tracks.

Our model, and Table 1, can be used to identify which, among the actual indoor world records, is the hardest or easiest to break, assuming the outdoor world record is a "benchmark performance" corresponding to the current "physiological limits" of males and female athletes respectively. Our 
404 model, in fact, calculates what time an athlete with the exact same fitness level and all the 405 conditions (drafting, motivation etc.) found during the outdoor world record could run on tracks 406 with different curve radiuses or on the straight. For males, it is evident that Daniel Komen's 3000 $407 \mathrm{~m}$ indoor world record is only $0.45 \%$ slower compared to the "physiological limit" he himself 408 reached on the outdoor track two years earlier. In order for an athlete to break the indoor world 409 record, they must be close to being able to run under the current outdoor world record. On the 410 other hand, the current $1500 \mathrm{~m}$ indoor world record is $1.78 \%$ slower compared to the 411 "physiological limit" set by Hicham el Guerrouj on an outdoor track and seems therefore relatively 412 easier to break. In order to break the current indoor world record by $0.01 \mathrm{~s}$, an athlete must be able 413 to run $3: 29.80$ on a $400 \mathrm{~m}$ outdoor track. For females, the $5000 \mathrm{~m}$ indoor world record is only $4140.59 \%$ slower compared to the "physiological limit" set by Tirunesh Dibaba on an outdoor track. 415 The women's outdoor $5000 \mathrm{~m}$ record is relatively harder to break compared to the $3000 \mathrm{~m}$ indoor 416 world record, 1.76\% slower compared to the "physiological limit" set by Junxia Wang on a $400 \mathrm{~m}$ 417 outdoor track.

418

Our prediction that a perfectly circular track is optimal for distance running performance concurs with Greene's model for sprint running (Greene and Monheit 1990). This is true for all racing 421 distances. A $1500 \mathrm{~m}$ runner is more affected by the velocity reduction on the curve $\left(v_{c}<<v_{s}\right)$ because of their faster average velocity compared to longer distances. However, runners competing in longer events have to perform more laps around the track (up to 25 laps for the $10000 \mathrm{~m}$ ). The number of laps seems therefore the dominant factor on the overall increased/decreased time as a function of curve radius. The time difference between a standard outdoor track $(r=36.8 \mathrm{~m})$ and a perfectly circular $400 \mathrm{~m}$ track $(r=63.66 \mathrm{~m}$ ) according to our model ranges between $-0.15 \mathrm{~s}$ for 1500 $\mathrm{m}$, and -0.86 for $10000 \mathrm{~m}$. When designing a stadium, an efficient use of the available space is critical: a standard track allows for a rectangular field in the center that can be used for multiple sports (football, soccer etc.) with a trivial sacrifice in terms of running performance. Interestingly, Australian football is played on an oval field that could accommodate a perfectly circular track on the outside and provide a direct confirmation of our predictions. It would also be interesting to see if and how a circular track, compared to the standard track, could influence race tactics.

433

434

435

436

437

438

439

440

Some insight into the validity of our model can also be gained by comparing the best performances of two world-class athletes (Jenny Simpson and Sydney Maree) when racing one mile (1609 m) indoors, outdoors and on a straight racecourse ( $5^{\text {th }}$ Avenue Mile, NY). Considering their outdoor personal best as their "benchmark performance" (4:17.30 for Simpson, 3:48.83 for Maree), our model predicts times on a $200 \mathrm{~m}$ indoor track of $4: 18.27,2.87 \%$ faster than the time of 4:25.91 run by Simpson, and 3:50.10, $0.99 \%$ faster compared to the time of 3:52.40 run by Maree. For a straight race, our model predicts times of $4: 16.98$, only $0.14 \%$ slower compared to the actual time of 4:16.6 run by Simpson and 3:48.40, only 0.39\% slower compared to 3:47.52 run by Maree. While the same considerations highlighted above must be taken in account when comparing different races (different years or racing seasons, different fitness levels), we must also take in account that the $5^{\text {th }}$ Avenue Mile is slightly net downhill which may explain why both our predictions seems slower than the actual race times.

449

The NCAA indoor track time conversion system provides another validity test. The NCAA conversion factors were developed using thousands of race performances, comparing times of the same athlete in different indoor facilities (Pederson et al. 2012). However, these conversions do 
450

451

452

453

454

455

456

457

458

459

460

461

462

463

464

465

466

467

468

469

470

471

472

473

474

475

476

477

478

479

480

481

482

483

484

485

486

487

488

489

490

491

492

493

494

495

not specifically take in account the exact curve radius of each indoor track. Rather, the NCAA categorizes them as "undersized" ( $<200 \mathrm{~m}$ per lap, like the Madison Square Garden track, which is $146.3 \mathrm{~m}$ per lap (Attwood 2012)), "standard" (200 m per lap) and "oversized" ( $>200 \mathrm{~m}$ per lap, typically $300 \mathrm{~m}$ (Pederson et al. 2012)). In addition, racing velocity is accounted for only in terms of male vs. female athletes and in terms of racing distances. For example, as the racing distance increases from $200 \mathrm{~m}$ to $5000 \mathrm{~m}$, the NCAA conversion factor from "oversized" to "standard" indoor tracks decreases from 1.0179 to 1.0107 for males, and from 1.0155 to 1.0077 for females. Despite these limitations, we can compare the NCAA conversions with our model predictions for $3000 \mathrm{~m}$ and $5000 \mathrm{~m}$ for male (Table 3A) and female (Table 3B) athletes.

Comparing standard $200 \mathrm{~m}$ vs. undersized indoor tracks, the difference between our model and NCAA conversions range from $0.01 \mathrm{~s}(<0.01 \%)$ for males in the $3000 \mathrm{~m}$, to $1.54 \mathrm{~s}(0.2 \%)$ for females in the $5000 \mathrm{~m}$. Comparing standard vs. oversized indoor tracks, the differences between the current model and NCAA conversions range from $3.39 \mathrm{~s}(0.63 \%)$ for females in the $3000 \mathrm{~m}$, to $6.52 \mathrm{~s}(0.78 \%)$ for males in the $5000 \mathrm{~m}$. While both NCAA conversion tables and our models agree on the overall effect of smaller vs larger radii on performance (i.e. the larger the radius, the better the overall time), our model predicts a slightly greater time when going from standard to undersized tracks, while it predicts smaller time reductions when going from standard to oversized tracks compared to NCAA conversion tables. These differences could be explained by the fact that NCAA tables provide an average conversion factor for a given race, independent of the actual performance of the athlete in that race, while in our model, velocity has a non-linear effect on the decreased or increased time on tracks of different radii (see Fig. 4).

When Eliud Kipchoge participated in the Breaking 2 attempt, he completed 17.4 laps around the Monza racetrack, totaling 105 curves (note that we divided the "Curva parabolica" into three sections, but even considering it as one single curve the total number of curves would still be 71). Our model predicts a trivial $1.52 \mathrm{~s}$ time difference between the Breaking 2 attempt and a marathon run on a straight racecourse. This is due to the fact that the smallest radius on the Monza racetrack is still $23 \mathrm{~m}$ (curve \# 1), a value $31 \%$ bigger than the radius of indoor tracks $(17.5 \mathrm{~m}$ ), therefore the velocity reduction on curves is hardly noticeable. A similar number of curves can be counted for two of the most famous marathon racecourses: $~ 50$ curves for the Berlin marathon (https://www.bmw-berlin-marathon.com/en/your-race/start-course-finish/course/) and $\sim 70$ for the London marathon (https://www.virginmoneylondonmarathon.com/en-gb/event-info/runnerinfo/). Even though we could not measure the radii of these curves, our model predicts that the increased time due to curve negotiation, compared to a straight racecourse, is negligible and the general perception of the magnitude of the effects of curves on road racing performance is not supported by our calculations.

\section{Limitations and future studies}

Running economy is affected by a multitude of biomechanical factors. In combination with the axial leg force that drives our model, contact time of the foot with the ground and the rate of force production (Roberts et al. 1998), antero-posterior ground reaction forces (Chang and Kram 1999), stride length (Cavanagh and Kram 1989) and stride frequency (Snyder and Farley 2011) all affect the energetic cost of running. When running at maximum speed on curves with small radii $(r \leq 6$ $\mathrm{m})$, runners increase their contact time, decrease antero-posterior ground reaction forces and stride

Peer) reviewing PDF | (2019:07:39890:1:2:NEW 7 Nov 2019) 
496 length compared to straight running (Chang and Kram 2007). It is unclear if these biomechanical 497 differences are maintained at sub-maximal speeds and at the larger radii. We have no knowledge 498 of studies that measured biomechanics and/or, more crucially, energetics of curve running that 499 could validate our model. In the future, we intend to empirically test a key assumption of our model 500 - that athletes run slower on curves compared to straight portions of a track during races. Indeed, 501 it is not clear if athletes can accurately sense their speed and metabolic rate with the precision and 502 time resolution required. It may be that athletes run at the same speed on straight and curved 503

504

505 sections and thus do not maintain a constant metabolic rate.

The data collected by Teunissen et al. (2007) that allowed us to derive Eq. 1 were collected at one fairly slow velocity $(3 \mathrm{~m} / \mathrm{s})$ on a treadmill, but to our knowledge there are no equivalent data for faster running velocities and none for overground running under different gravity conditions. In addition, we extrapolated Eq. 1 beyond normal gravity, assuming the same slope is maintained when the average axial force acting on the runner is increased $\left(\overline{F_{a}}>1 B W\right)$. Additional experiments are needed to quantify the effects of different velocities and increased gravity on Eq. 5111 and verify our assumption. In addition, our model does not distinguish between male and female athletes. While Eq. 1 can be applied to both male and female athletes, given that Teunissen et al. (2007) included both sexes in their study, Eq. 7 was derived for male runners only (Kipp et al. 2019). Generally, studies find that males are slightly more economical than females at matched absolute running velocities (Daniels and Daniels 1992). Eq. 7 should therefore be adapted for female athletes with a different set of parameters that take in account these differences.

Our extrapolation of the Kipp et al. (2019) equation seems reasonable but it would be preferable to obtain empirical measurements of oxygen uptake or metabolic rate for elite athletes at faster running speeds that are closer to the world record performances. In order to run $42195 \mathrm{~m}$ on the Monza racetrack in a total time $t_{\text {Monza }}=7225 \mathrm{~s}$ or $5.84 \mathrm{~m} / \mathrm{s}$, Equation 7 predicts that Eliud Kipchoge sustained a rate of oxygen uptake $V \dot{O}_{2 s}=80.87 \mathrm{mlO}_{2} / \mathrm{min} / \mathrm{kg}$ (see algorithm 2 in Appendix for details). This incredible value suggests that either that the Pugh (1970) factor for air resistance is too large or that Kipchoge is much more economical runner that the subjects tested by Kipp et al. (2019). Fortunately, the absolute value does not affect our calculations of the effects of curve running.

526

527

When we model an athlete transitioning from straight to curved running, such as when running on a track or on a non-straight road race, we assume that the change in velocity (from $v_{s}$ to $v_{c}$ and vice-versa) is instantaneous, i.e. there is no deceleration or acceleration phase between straight and curved portions. This assumption may be reasonable for larger radii, such as outdoor or indoor racing tracks. If $\mathrm{r}=17.5 \mathrm{~m}$, when the velocity on the straight is $v_{s}=7.00 \mathrm{~m} / \mathrm{s}$, the velocity on the curve is reduced to $v_{c}=6.91 \mathrm{~m} / \mathrm{s}$, allowing an athlete to decelerate and re-accelerate in one single step. But, for much smaller radii (e.g. $\mathrm{r}=1 \mathrm{~m}$ ) when the velocity on the straight is $v_{s}=7.00 \mathrm{~m} / \mathrm{s}$, the velocity on the curve is $v_{c}=4.69 \mathrm{~m} / \mathrm{s}$, an athlete would likely need more than one step to decelerate and then re-accelerate). Non-trivial decelerations and accelerations increase the metabolic cost of running (di Prampero et al. 2005) and should therefore be factored into our model, especially for smaller $(<6 \mathrm{~m})$ curve radiuses. This approach, while theoretically possible, can lead to accurate calculations only if the exact values of deceleration and accelerations are 
540 known. Future studies (from video and/or from lab-based measurements) could provide such

541

542

543

544

545

546

547

548

549

550

551

552

553

554

555

556

557

558

559

560

561

562

563

564

565

566

567

568

569

570

571

572

573

574

575

576

577

578

579

580

581

582

583

information and fill this gap to create a more realistic model.

When an athlete is running on a curve with large radius, even for faster $(>7 \mathrm{~m} / \mathrm{s})$ velocities, the increase in axial force $\overline{F_{a}}$ is relatively small (see Fig. 1b) and it is reasonable to assume that, as modeled in this paper, the limiting factor on $v_{c}$ is mainly the metabolic cost of running. However, at smaller radii the increase in $\overline{F_{a}}$ is much more marked (for $\mathrm{r}=1 \mathrm{~m}$, when $v_{s}=7.00 \mathrm{~m} / \mathrm{s}$ and $v_{c}=4.69$ $\left.\mathrm{m} / \mathrm{s}, \overline{F_{a}}=2.45 \mathrm{BW}\right) . \overline{F_{a}}$ is the axial force calculated over a full step, assuming a duty factor of $45 \%$ (Chang and Kram 2007) the average force during contact reaches an even higher value of 2.72 BW. Chang and Kram (2007) measured velocities and ground reaction forces of recreational athletes sprinting on the straight and on curves of small ( $6 \mathrm{~m}$ or less) radii. While subjects were able to reach $v_{s}=7.70 \mathrm{~m} / \mathrm{s}$ on the straight, the maximum velocity on a curve when $\mathrm{r}=1 \mathrm{~m}$ was only $2.99 \mathrm{~m} / \mathrm{s}$, well below the velocity predicted by our model. In addition, the peak axial forces reached only $1.87 \mathrm{BW}$ for the inside leg and 2.25 BW for the outside leg. In the Chang and Kram (2007) study, subjects were instructed to run as fast as possible but only for a very limited amount of time. Therefore, the maximum velocity they were able to attain on curves was not limited by metabolic cost, but by other constraints. Chang and Kram (2007) concluded that during small radius curve sprinting, the ability to generate force, in particular from the inside leg, limits maximum curve velocity. When athletes run on curves at sub-maximal speeds (i.e. for a prolonged period of time), it is likely that both mechanisms play roles. When transitioning from straight to curved running, at larger radii, the main driving factor in the velocity reduction is maintaining a constant metabolic rate. But, at progressively smaller radii, the increase of centripetal, and therefore axial forces, is amplified and velocity is further reduced as the athlete is limited by his/her ability to generate forces.

A third effect not included in our model is the difference between flat and banked curves. Eq. 1 and Eq. 7, in particular, apply only to straight running. When we calculate the average axial leg force $\overline{F_{a}}$ of an athlete running on a curve, we assume that the body is aligned with $\overline{F_{a}}$ (see Fig.1, inset) and the ankle remains in the sagittal plane, similar to straightline running. In other words, we assume that the curve is banked and $\overline{F_{a}}$ is always perpendicular to the running surface. Greene (1987) provided evidence that this is the ideal condition for sprint running and showed that any deviation of the banking angle, resulting in a misalignment of $\overline{F_{a}}$ and the running surface, results in a further reduction of velocity on the curve $v_{c}$. For example, if $v_{c}=10 \mathrm{~m} / \mathrm{s}$ and $\mathrm{r}=17.5 \mathrm{~m}$, the angle of $\overline{F_{a}}$ with the vertical is $30^{\circ}$. A sprinter running on a flat (unbanked) curve would slow down by $1.1 \mathrm{~m} / \mathrm{s}$ compared to a curve with a $30^{\circ}$ bank (Greene, 1987). Since this effect is much less important at distance running velocities $(<7 \mathrm{~m} / \mathrm{s})$ and for large radii (e.g. Monza racetrack), we did not account for this further reduction in $v_{c}$ on flat, or non ideally-banked, curves.

\section{Conclusions}

Our model assumes that runners reduce their velocity on curves, compared to straight running, to maintain a constant metabolic rate for the whole duration of the event. This reduction is marked for smaller curve radii, such as indoor tracks, and at faster velocities. The effect becomes

Peer) reviewing PDF | (2019:07:39890:1:2:NEW 7 Nov 2019) 
584 negligible, in terms of overall performance, for larger radii and slower speeds, such as those seen 585 in city marathons. The general perception of the magnitude of the effects of curves on road racing 586 performance is not supported by our calculations

587

588 


\section{Acknowledgements}

590

591 The authors thank Brett Kirby, Ph.D. for providing the blueprints of Monza racetrack, and Owen

592 Beck, Ph.D. and Shalaya Kipp, M.S. for their helpful critiques of an earlier version of this 593 manuscript.

\section{Conflict of interest}

596

597 The authors declare that they have no conflicts of interest. 
598

599

600

601

602

603

604

605

606

607

608

609

610

611

612

613

614

615

616

617

618

619

620

621

622

623

624

625

626

627

628

629

630

631

632

633

634

635

636

637

638

639

640

641
References

Alexander RM (2002) Stability and manoeuvrability of terrestrial vertebrates. Integr Comp Biol 42:158-164 doi:10.1093/icb/42.1.158

Arellano CJ, Kram R (2014) Partitioning the metabolic cost of human running: a task-by-task approach. Integr Biol 54:1084-1098 doi:10.1093/icb/icu033

Attwood E (2012) NCAA institutes indexing system for 2012-13 indoor track and field. https://www.athleticbusiness.com/college/ncaa-institutes-indexing-system-for-2012-13indoor-track-and-field.html. Accessed 3/1/2019

Bassett DR, Jr., Howley ET (2000) Limiting factors for maximum oxygen uptake and determinants of endurance performance. Med Sci Sports Exerc 32:70-84

Beck ON, Kipp S, Byrnes WC, Kram R (2018) Use aerobic energy expenditure instead of oxygen uptake to quantify exercise intensity and predict endurance performance. J Appl Physiol 125:672-674 doi:10.1152/japplphysiol.00940.2017

Cavanagh PR, Kram R (1989) Stride length in distance running: velocity, body dimensions, and added mass effects. Med Sci Sports Exerc 21:467-479

Chang YH, Kram R (1999) Metabolic cost of generating horizontal forces during human running. J Appl Physiol 86:1657-1662

Chang YH, Kram R (2007) Limitations to maximum running speed on flat curves. J Exp Biol 210:971-982 doi:10.1242/jeb.02728

Churchill SM, Trewartha G, Bezodis IN, Salo AI (2016) Force production during maximal effort bend sprinting: Theory vs reality. Scand J Med Sci Sports 26:1171-1179 doi:10.1111/sms.12559

Coyle EF (1995) Integration of the physiological factors determining endurance performance ability. Exerc Sport Sci Rev 23:25-63

Daniels J, Daniels N (1992) Running economy of elite male and elite female runners. Med Sci Sports Exerc 24:483-489

di Prampero PE, Fusi S, Sepulcri L, Morin JB, Belli A, Antonutto G (2005) Sprint running: a new energetic approach. J Exp Biol 208:2809-2816 doi:10.1242/jeb.01700

Ferretti G, Bringard A, Perini R (2011) An analysis of performance in human locomotion. Eur J Appl Physiol 111:391-401 doi:10.1007/s00421-010-1482-y

Fletcher JR, Esau SP, Macintosh BR (2009) Economy of running: beyond the measurement of oxygen uptake. J Appl Physiol 107:1918-1922 doi:10.1152/japplphysiol.00307.2009

Giovanelli N, Ortiz AL, Henninger K, Kram R (2016) Energetics of vertical kilometer foot races; is steeper cheaper? J Appl Physiol 120:370-375 doi:10.1152/japplphysiol.00546.2015

Greene PR (1985) Running on flat turns: experiments, theory, and applications. J Biomech Eng 107:96-103

Greene PR (1987) Sprinting with banked turns. J Biomech 20:667-680

Greene PR, Monheit MA (1990) Optimal geometry for oval sprint tracks J Biomech 23:447-452

Hamill J, Murphy M, Sussman D (1987) The effects of track turns on lower extremity function

Journal of applied biomechanics 3:276-286

Hayati H, Eager D, Jusufi A, Brown T (2017) A study of rapid tetrapod running and turning dynamics utilizing inertial measurement units in greyhound sprinting. ASME DETC 67691 V003T13A006 
642 Hoogkamer W, Kipp S, Spiering BA, Kram R (2016) Altered running economy directly

643 translates to altered distance-running performance. Med Sci Sports Exerc 48:2175-2180

644 doi:10.1249/MSS.0000000000001012

645

646

647

648

649

650

651

652

653

654

655

656

657

658

659

660

661

662

663

664

665

666

667

668

669

670

671

672

673

674

675

676

677

678

679

680

681

682

683

684

685

686

687

Hoogkamer W, Kram R, Arellano CJ (2017) How biomechanical improvements in running economy could break the 2-hour marathon barrier. Sports Med 47:1739-1750, 2017. doi: 10.1007/s40279-017-0708-0

Hoogkamer W, Snyder KL, Arellano CJ (2019) Reflecting on Eliud Kipchoge's marathon world record: an update to our model of cooperative drafting and its potential for a sub-2-hour performance. Sports Med 49:167-170 doi:10.1007/s40279-019-01056-2

Hoogkamer W, Taboga P, Kram R (2014) Applying the cost of generating force hypothesis to uphill running PeerJ 2:e482 doi:10.7717/peerj.482

IAAF The Measurement of Road Race Courses https://www.iaaf.org/download/download?filename=1d445793-24b4-4821-98e438fc55b9f8ef.pdf\&urlslug=IAAF\%20Road\%20Running\%20Manual.

IAAF (2008a) IAAF Track and Field Facilities Manual 2008 - chapters 4-8.

IAAF (2008b) Track and field facilities manual - chapters 1-3

IAAF (2018) IAAF Competition Rules 2018-2019

Joyner MJ (1991) Modeling: optimal marathon performance on the basis of physiological factors. J Appl Physiol 70:683-687 doi:10.1152/jappl.1991.70.2.683

Joyner MJ, Coyle EF (2008) Endurance exercise performance: the physiology of champions. J Physiol 586:35-44 doi:10.1113/jphysiol.2007.143834

Kerdok AE, Biewener AA, McMahon TA, Weyand PG, Herr HM (2002) Energetics and mechanics of human running on surfaces of different stiffnesses. J Appl Physiol 92:469478 doi:10.1152/japplphysiol.01164.2000

Kipp S, Byrnes WC, Kram R (2018a) Calculating metabolic energy expenditure across a wide range of exercise intensities: the equation matters. Appl Physiol Nutr Metab 43:639-642 doi:10.1139/apnm-2017-0781

Kipp S, Grabowski AM, Kram R (2018b) What determines the metabolic cost of human running across a wide range of velocities? J Exp Biol 221 doi:10.1242/jeb.184218

Kipp S, Kram R, Hoogkamer W (2019) Extrapolating metabolic savings in running: implications for performance predictions. Front Physiol 10:79 doi:10.3389/fphys.2019.00079

Kram R, Taylor CR (1990) Energetics of running: a new perspective. Nature 346:265-267 doi:10.1038/346265a0

Luo G, Stefanyshyn D (2011) Identification of critical traction values for maximum athletic performance. Footwear Sci 3:127-138 doi:10.1080/19424280.2011.639807

Luo G, Stefanyshyn D (2012) Limb force and non-sagittal plane joint moments during maximum-effort curve sprint running in humans. J Exp Biol 215:4314-4321 doi:10.1242/jeb.073833

Pederson K, Larson G, Jones S, Podkaminer B (2012) Indoor facility indexing for NCAA running events performances

Pugh LG (1970) Oxygen intake in track and treadmill running with observations on the effect of air resistance. J Physiol 207:823-835

Roberts TJ, Kram R, Weyand PG, Taylor CR (1998) Energetics of bipedal running. I. Metabolic cost of generating force. J Exp Biol 201:2745-2751

Shaw AJ, Ingham SA, Folland JP (2014) The valid measurement of running economy in runners. Med Sci Sports Exerc 46:1968-1973 doi:10.1249/MSS.0000000000000311

PeerJ reviewing PDF | (2019:07:39890:1:2:NEW 7 Nov 2019) 
688 Snyder KL, Farley CT (2011) Energetically optimal stride frequency in running: the effects of 689 incline and decline. J Exp Biol 214:2089-2095 doi:10.1242/jeb.053157

690 Teunissen LP, Grabowski A, Kram R (2007) Effects of independently altering body weight and 691

692

693 Usherwood JR, Wilson AM (2005) Biomechanics: no force limit on greyhound sprint speed. $694 \quad$ Nature 438:753-754 doi:10.1038/438753a

695 Wilson R, Griffiths I, Legg P, Friswell M, Bidder OR, Halsey LG, Lambertucci EL, Shepard E 696 697 (2013) Turn costs change the value of animal search paths. Ecol Letters 16:1145-1150 doi:10.1111/ele.12149 


\section{Table $\mathbf{1}$ (on next page)}

Actual and predicted world records at various racing distances for males $(A)$ and females (B).

A $400 \mathrm{~m}$ outdoor track is used as the baseline reference for the record predictions on a 200 $\mathrm{m}$ indoor track and straight path races. The curve radii are the actual radii run by athletes for indoor ( $r=17.5 \mathrm{~m}$, (IAAF 2008a)) and outdoor tracks ( $\mathrm{r}=36.8 \mathrm{~m}$, (IAAF 2008b)) respectively. $10000 \mathrm{~m}$ is not officially run on an indoor track (IAAF 2018). 
1 A

\begin{tabular}{|c|c|c|c|c|c|c|c|c|c|}
\hline Males & \multicolumn{2}{|c|}{$1500 \mathrm{~m}$} & \multicolumn{2}{|c|}{$3000 \mathrm{~m}$} & \multicolumn{3}{|c|}{$5000 \mathrm{~m}$} & \multicolumn{2}{|c|}{$10000 \mathrm{~m}$} \\
\hline $\begin{array}{c}\text { Indoor } \\
\text { track } \\
(\mathrm{r}=17.5 \mathrm{~m})\end{array}$ & $\begin{array}{l}\text { Actual } \\
\text { record: } \\
3: 31.04\end{array}$ & $\begin{array}{c}\text { Predicted } \\
\text { record: } \\
3: 27.32\end{array}$ & $\begin{array}{l}\text { Actual } \\
\text { record: } \\
7: 24.90\end{array}$ & \begin{tabular}{|c|} 
Predicted \\
record: \\
$7: 22.88$ \\
\end{tabular} & & $\begin{array}{l}\text { ual } \\
\text { ord: } \\
9.60\end{array}$ & $\begin{array}{l}\text { Predicted } \\
\text { record: } \\
\text { 12:40.78 }\end{array}$ & $\begin{array}{c}\text { Actual } \\
\text { record: } \\
\text { N.A. }\end{array}$ & $\begin{array}{l}\text { Predicted } \\
\text { record: } \\
\text { 26:23.78 }\end{array}$ \\
\hline $\begin{array}{c}\text { Outdoor } \\
\text { Track } \\
(\mathrm{r}=36.8 \mathrm{~m})\end{array}$ & \multicolumn{2}{|c|}{$3: 26.00$} & \multicolumn{2}{|c|}{$7: 20.67$} & \multicolumn{3}{|c|}{$12: 37.35$} & \multicolumn{2}{|c|}{$26: 17.53$} \\
\hline Straight & \multicolumn{2}{|c|}{$\begin{array}{c}\text { Predicted record: } \\
\text { 3:25.59 }\end{array}$} & \multicolumn{3}{|c|}{$\begin{array}{c}\text { Predicted record: } \\
7: 19.93\end{array}$} & \multicolumn{2}{|c|}{$\begin{array}{c}\text { Predicted record: } \\
12: 36.20\end{array}$} & & $\begin{array}{l}\text { redicted } \\
\text { record: } \\
26: 15.47\end{array}$ \\
\hline
\end{tabular}

2

3 B

4

\begin{tabular}{|c|c|c|c|c|c|c|c|c|}
\hline Females & \multicolumn{2}{|c|}{$1500 \mathrm{~m}$} & \multicolumn{2}{|c|}{$3000 \mathrm{~m}$} & \multicolumn{2}{|c|}{$5000 \mathrm{~m}$} & \multicolumn{2}{|c|}{$10000 \mathrm{~m}$} \\
\hline $\begin{array}{c}\text { Indoor } \\
\text { track } \\
(\mathrm{r}=17.5 \mathrm{~m})\end{array}$ & $\begin{array}{l}\text { Actual } \\
\text { record: } \\
3: 55.17\end{array}$ & $\begin{array}{c}\text { Predicted } \\
\text { record: } \\
\text { 3:51.09 }\end{array}$ & $\begin{array}{l}\text { Actual } \\
\text { record: } \\
8: 16.60\end{array}$ & $\begin{array}{c}\text { Predicted } \\
\text { record: } \\
\text { 8:07.87 }\end{array}$ & $\begin{array}{l}\text { Actual } \\
\text { record: } \\
14: 18.86\end{array}$ & $\begin{array}{l}\text { Predicted } \\
\text { record: } \\
14: 13.77\end{array}$ & $\begin{array}{l}\text { Actual } \\
\text { record: } \\
\text { N.A. }\end{array}$ & $\begin{array}{l}\text { Predicted } \\
\text { record: } \\
29: 22.32\end{array}$ \\
\hline $\begin{array}{c}\text { Outdoor } \\
\text { Track } \\
(\mathrm{r}=36.8 \mathrm{~m})\end{array}$ & \multicolumn{2}{|c|}{$3: 50.07$} & \multicolumn{2}{|c|}{$8: 06.11$} & \multicolumn{2}{|c|}{$14: 11.15$} & \multicolumn{2}{|c|}{$29: 17.45$} \\
\hline Straight & \multicolumn{2}{|c|}{$\begin{array}{c}\text { Predicted record: } \\
3: 49.76\end{array}$} & \multicolumn{2}{|c|}{$\begin{array}{c}\text { Predicted record: } \\
\text { 8:05.53 }\end{array}$} & \multicolumn{2}{|c|}{$\begin{array}{c}\text { Predicted record: } \\
14: 10.30 \\
\end{array}$} & \multicolumn{2}{|c|}{$\begin{array}{c}\text { Predicted record: } \\
29: 15.88\end{array}$} \\
\hline
\end{tabular}

6 Table 1. Actual and predicted world records at various racing distances for males (A) and females 7 (B). A $400 \mathrm{~m}$ outdoor track is used as the baseline reference for the record predictions on a $200 \mathrm{~m}$ 8 indoor track and straight path races. The curve radii are the actual radii run by athletes for indoor $9 \quad(\mathrm{r}=17.5 \mathrm{~m},($ IAAF 2008a)) and outdoor tracks ( $\mathrm{r}=36.8 \mathrm{~m}$, (IAAF 2008b)) respectively. $10000 \mathrm{~m}$ is 10 not officially run on an indoor track (IAAF 2018).

11 12 


\section{Table 2 (on next page)}

Radii and distances of each of the six curves we identified for the Monza racetrack

The Straight row represents the sum of all the straight portions of the racetrack. For each portion, we calculated the running velocities on the straight and on each of the curved portions of the track according assuming that Eliud Kipchoge maintained a constant $\mathrm{VO}_{2 c}=\mathrm{VO}_{2 s}$ (see algorithm 2 in Appendix for details). 
1

2

\begin{tabular}{|c|c|c|c|}
\hline Curve \# & Radius (m) & $\begin{array}{c}\text { Distance } \\
(\mathrm{m})\end{array}$ & $\begin{array}{c}\text { Velocity } \\
(\mathrm{m} / \mathrm{s})\end{array}$ \\
\hline 1 & 23 & 32 & 5.8165 \\
\hline 2 & 24 & 21 & 5.8185 \\
\hline 3 & 25 & 62 & 5.8202 \\
\hline 4 & 350 & 116.7 & 5.8413 \\
\hline 5 & 164 & 151 & 5.8409 \\
\hline 6 & 80 & 134.7 & 5.8393 \\
\hline \multicolumn{4}{|l}{} \\
\hline Straight & 1907 & 5.8414 \\
\hline
\end{tabular}

3

4 Table 2. Radii and distances of each of the six curves we identified for the Monza racetrack, the 5 Straight row represents the sum of all the straight portions of the racetrack. For each portion, we 6 calculated the running velocities on the straight and on each of the curved portions of the track 7 according assuming that Eliud Kipchoge maintained a constant $\dot{V} O_{2 c}=\dot{V} O_{2 s}$ (see algorithm 2 in 8 Appendix for details). 


\section{Table 3 (on next page)}

Comparison of the NCAA conversion factors vs. the current proposed model for $3000 \mathrm{~m}$ and $5000 \mathrm{~m}$ racing distances for males $(A)$ and females (B).

For each distance and for each sex, we identified sample performances on a standard indoor track (200 m per lap, curve radius $r=17.5 \mathrm{~m}$ ) and converted them to an undersized track (corresponding to the Madison Square Garden indoor track, $146.3 \mathrm{~m}$ per lap and $\mathrm{r}=11.7 \mathrm{~m}$ (Attwood 2012)and to an oversized track (300 m per lap, $r=35$ m, https://www.pl-linemarking.co.uk/300-metre-track-line-marking.html ) using NCAA conversion tables and our model. Performances are reported in minutes:seconds. hundredths. 


\begin{tabular}{|c|c|c|c|c|}
\hline \multirow{2}{*}{$\begin{array}{c}\text { Males } \\
\text { Undersized indoor } \\
\text { track } \\
\left(\begin{array}{l}\text { (1 lap } 146.3 \mathrm{~m}, \mathrm{r} \\
=11.7 \mathrm{~m})\end{array}\right.\end{array}$} & \multicolumn{2}{|c|}{$3000 \mathrm{~m}$} & \multicolumn{2}{|c|}{$5000 \mathrm{~m}$} \\
\hline & $\begin{array}{l}\text { NCAA: } \\
8: 02.27\end{array}$ & $\begin{array}{l}\text { Current } \\
\text { model: } \\
8: 02.28\end{array}$ & $\begin{array}{l}\text { NCAA: } \\
14: 03.29\end{array}$ & $\begin{array}{l}\text { Current } \\
\text { model: } \\
14: 03.45\end{array}$ \\
\hline $\begin{array}{c}\text { Standard indoor } \\
\text { track } \\
(1 \mathrm{lap}=200 \mathrm{~m} \\
\mathrm{r}=17.5 \mathrm{~m})\end{array}$ & \multicolumn{2}{|c|}{$8: 00.00$} & \multicolumn{2}{|c|}{$14: 00.00$} \\
\hline $\begin{array}{l}\text { Oversized indoor } \\
\text { track } \\
(1 \text { lap }=300 \mathrm{~m} \\
\mathrm{r}=35 \mathrm{~m})\end{array}$ & $\begin{array}{l}\text { NCAA: } \\
7: 54.50\end{array}$ & $\begin{array}{l}\text { Current } \\
\text { model: } \\
7: 58.40\end{array}$ & $\begin{array}{l}\text { NCAA: } \\
13: 51.11\end{array}$ & $\begin{array}{l}\text { Current } \\
\text { model: } \\
13: 57.63\end{array}$ \\
\hline
\end{tabular}

16

17

B

18

20

21

22

23

24

25

26

27

28

29

30

\begin{tabular}{|c|c|c|c|c|}
\hline Females & \multicolumn{2}{|c|}{$3000 \mathrm{~m}$} & \multicolumn{2}{|c|}{$5000 \mathrm{~m}$} \\
\hline $\begin{array}{l}\text { Undersized indoor } \\
\text { track } \\
\begin{array}{c}(1 \text { lap } 146.3 \mathrm{~m}, \mathrm{r} \\
=11.7 \mathrm{~m})\end{array}\end{array}$ & $\begin{array}{l}\text { NCAA: } \\
9: 01.03\end{array}$ & $\begin{array}{l}\text { Current } \\
\text { model: } \\
9: 01.79\end{array}$ & $\begin{array}{l}\text { NCAA: } \\
16: 01.06\end{array}$ & $\begin{array}{l}\text { Current } \\
\text { model: } \\
16: 02.60\end{array}$ \\
\hline $\begin{array}{c}\text { Standard indoor } \\
\text { track } \\
(1 \mathrm{lap}=200 \mathrm{~m} \\
\mathrm{r}=17.5 \mathrm{~m})\end{array}$ & \multicolumn{2}{|c|}{$9: 00.00$} & \multicolumn{2}{|c|}{$16: 00.00$} \\
\hline $\begin{array}{l}\text { Oversized indoor } \\
\text { track } \\
(1 \text { lap }=300 \mathrm{~m} \\
\mathrm{r}=35 \mathrm{~m})\end{array}$ & $\begin{array}{l}\text { NCAA: } \\
8: 55.40\end{array}$ & $\begin{array}{l}\text { Current } \\
\text { model: } \\
8: 58.79\end{array}$ & $\begin{array}{l}\text { NCAA: } \\
15: 52.66\end{array}$ & $\begin{array}{l}\text { Current } \\
\text { model: } \\
15: 58.25\end{array}$ \\
\hline
\end{tabular}

Table 3. Comparison of the NCAA conversion factors vs. the current proposed model for $3000 \mathrm{~m}$ and $5000 \mathrm{~m}$ racing distances for males (A) and females (B). For each distance and for each sex, we identified sample performances on a standard indoor track ( $200 \mathrm{~m}$ per lap, curve radius $\mathrm{r}=17.5$ $\mathrm{m}$ ) and converted them to an undersized track (corresponding to the Madison Square Garden indoor track, $146.3 \mathrm{~m}$ per lap and $\mathrm{r}=11.7 \mathrm{~m}$ (Attwood 2012) and to an oversized track (300 m per lap, $\mathrm{r}=35 \mathrm{~m}$, https://www.pl-linemarking.co.uk/300-metre-track-line-marking.html) using NCAA conversion tables and our model. Performances are reported in minutes:seconds.hundredths. 


\section{Figure 1}

Axial leg force $F_{a}$ as a function of curve radius $r(A)$, and running velocity $v(B)$. Fractional increase in gross rate of metabolic energy expenditure $f$ as a function of curve radius $r(C)$, and velocity $v(D)$.

The standard radii for indoor and outdoor running tracks, are $r=17.5 \mathrm{~m}$ and $r=36.8 \mathrm{~m}$ respectively. Inset figure representing centripetal $\left(F_{c}\right)$, vertical $\left(F_{v}\right)$ and axial $\left(F_{a}\right)$ forces, modified with permission from Chang and Kram (2007). Values of $F_{a}$ and $f$ when running at fast velocities $(>8 \mathrm{~m} / \mathrm{s})$ on small radii $(<6 \mathrm{~m})$ are not physiological, we depict them only to illustrate the effects of velocity and radius in extreme conditions. 
A

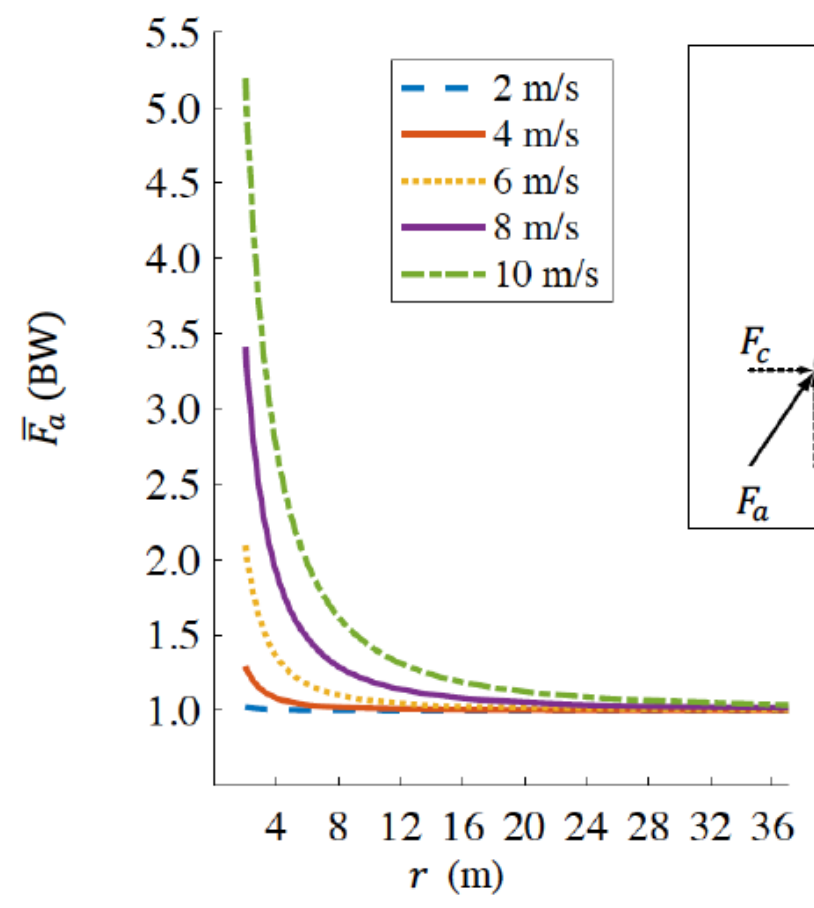

C

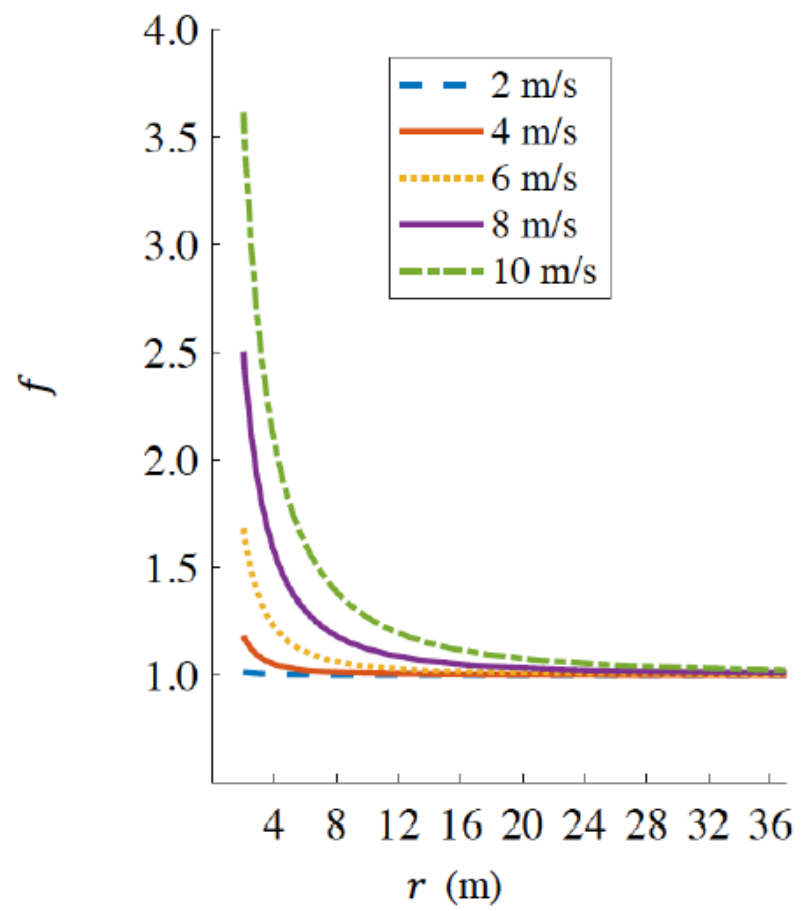

B
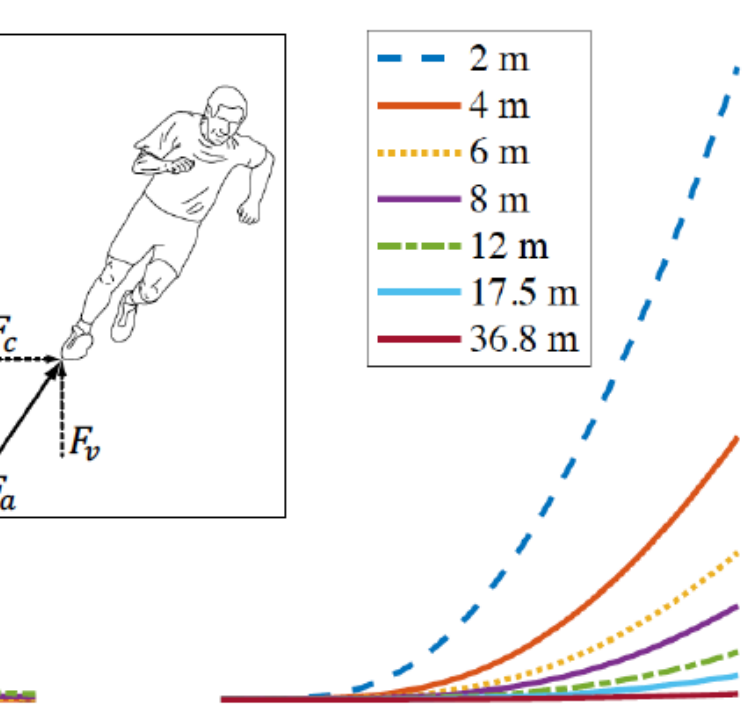

5.5

5.0

4.5

4.0

3.5

3.0

$\sum_{10.0}^{\infty}$

2.5

2.0

1.5

1.0

D

$$
v(\mathrm{~m} / \mathrm{s})
$$

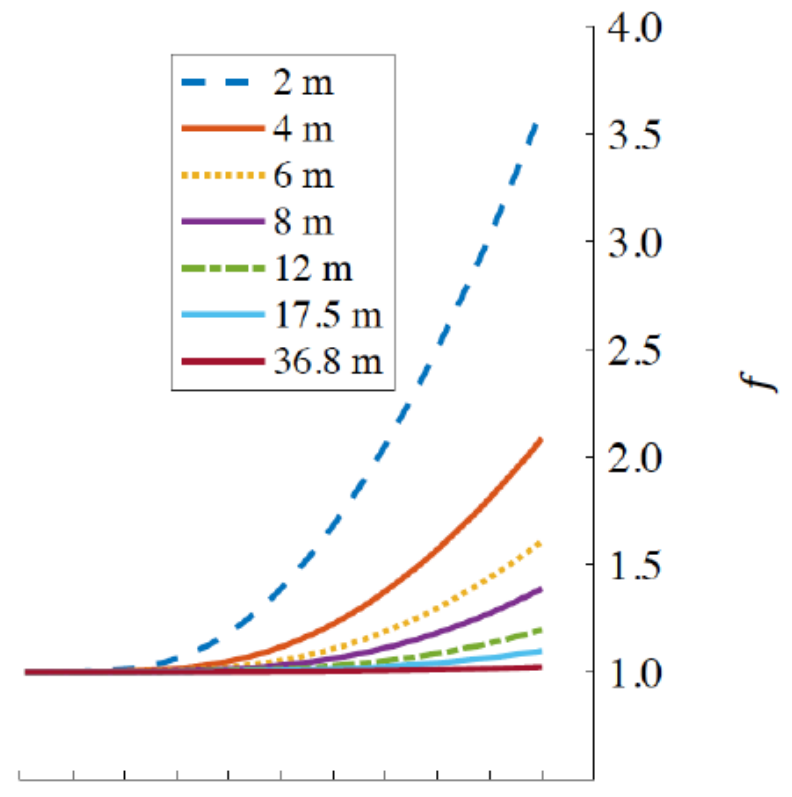

$\begin{array}{ccccccccccc}0 & 1 & 2 & 3 & 4 & 5 & 6 & 7 & 8 & 9 & 10 \\ v & (\mathrm{~m} / \mathrm{s}) & & & & \end{array}$ 
Figure 2

Outline of standard outdoor and indoor tracks (A) and of the Monza racetrack utilized during the "Breaking 2" project (B).

For indoor track: $r_{\text {indoor }}=17.5 \mathrm{~m}$ and the distance of one lap $d_{\text {lap,indoor }}=200 \mathrm{~m}$. For outdoor track: $r_{\text {outdoor }}=36.8 \mathrm{~m}$ and $d_{\text {lap,outdoor }}=400 \mathrm{~m}$. We divided the south curve ("Curva parabolica") into three different portions (labeled 4, 5 and 6) in order to account for the non-constant radius of this specific section. Panels $A$ and $B$ have different scales.

A
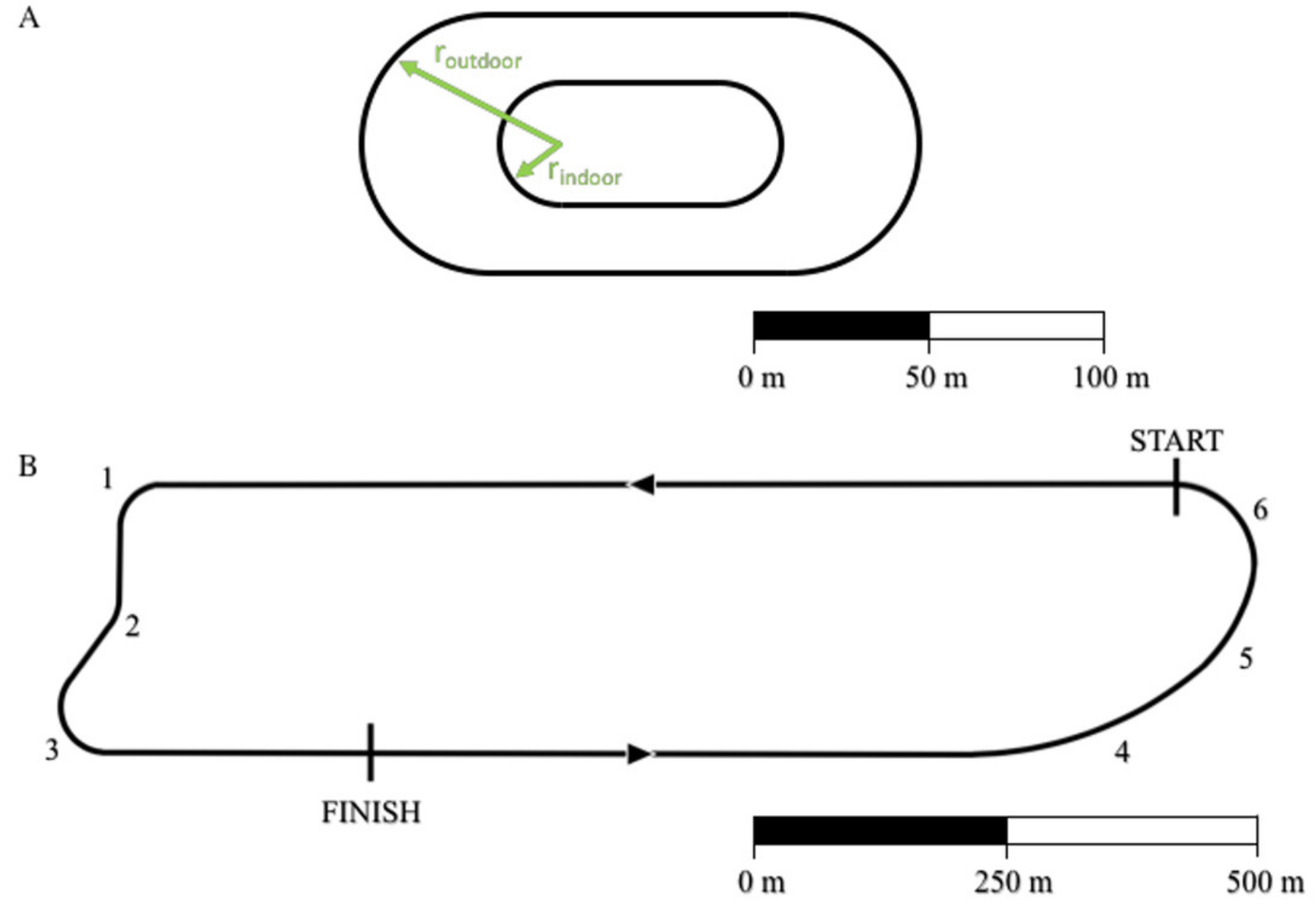


\section{Figure 3}

Increased time for a $180^{\circ}$ turn as a function of radius

We selected three velocities: $v_{1}=7.3 \mathrm{~m} / \mathrm{s}$ (dashed line, corresponding to Hicham el Guerrouj's $1500 \mathrm{~m}$ world record), $\mathrm{v}_{2}=6.1 \mathrm{~m} / \mathrm{s}$ (continuous line, corresponding to men's half marathon world record) and $\mathrm{v}_{3}=4 \mathrm{~m} / \mathrm{s}$ (dash-dotted line). For each line, the maximum Delta $\mathrm{t}$ is located at $r_{1}=2.8 \mathrm{~m}, \mathrm{r}_{2}=1.9 \mathrm{~m}$ and $r_{3}=0.8 \mathrm{~m}$ for $\mathrm{v}_{1}, \mathrm{v}_{2}$ and $\mathrm{v}_{3}$ respectively. Caution should be used when applying our model at very small radii (<6 m). Chang and Kram (2007)report a maximum sprinting velocity $v=5.66 \mathrm{~m} / \mathrm{s}$ for $=6 \mathrm{~m}$, while our model predicts an unrealistic sustained velocity $\mathrm{v}_{\mathrm{c}}=6.71 \mathrm{~m} / \mathrm{s}$. 


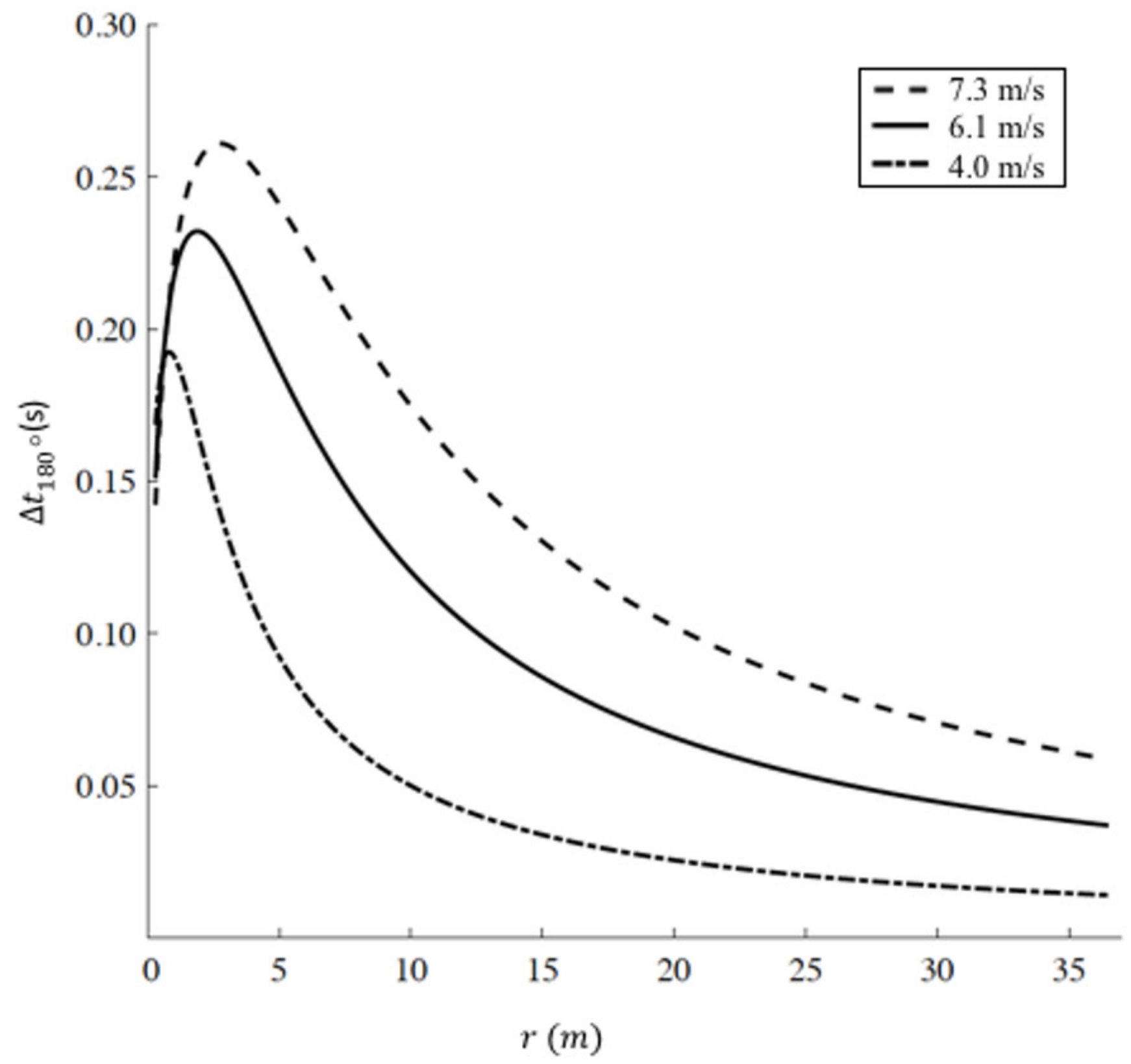


Figure 4

Time difference (delta t) for a given racing distance $(1500 \mathrm{~m}, 5000 \mathrm{~m}$ and $10000 \mathrm{~m}$ in panel $A$, half marathon and marathon in panel B) as a function of velocity (v).

For a given racing distance, run on a $400 \mathrm{~m}$ outdoor track (curve radius $r_{\text {outdoor }}=36.8 \mathrm{~m}$ ), we calculated how much time would increase (delta $\mathrm{t}>0$ ) on a $200 \mathrm{~m}$ indoor track (curve radius $r_{\text {indoor }}=17.5 \mathrm{~m}$ ), or decrease (delta $t<0$ ) on a straight path. For each racing distance, the maximum velocity corresponds to the respective current men's world record.

A

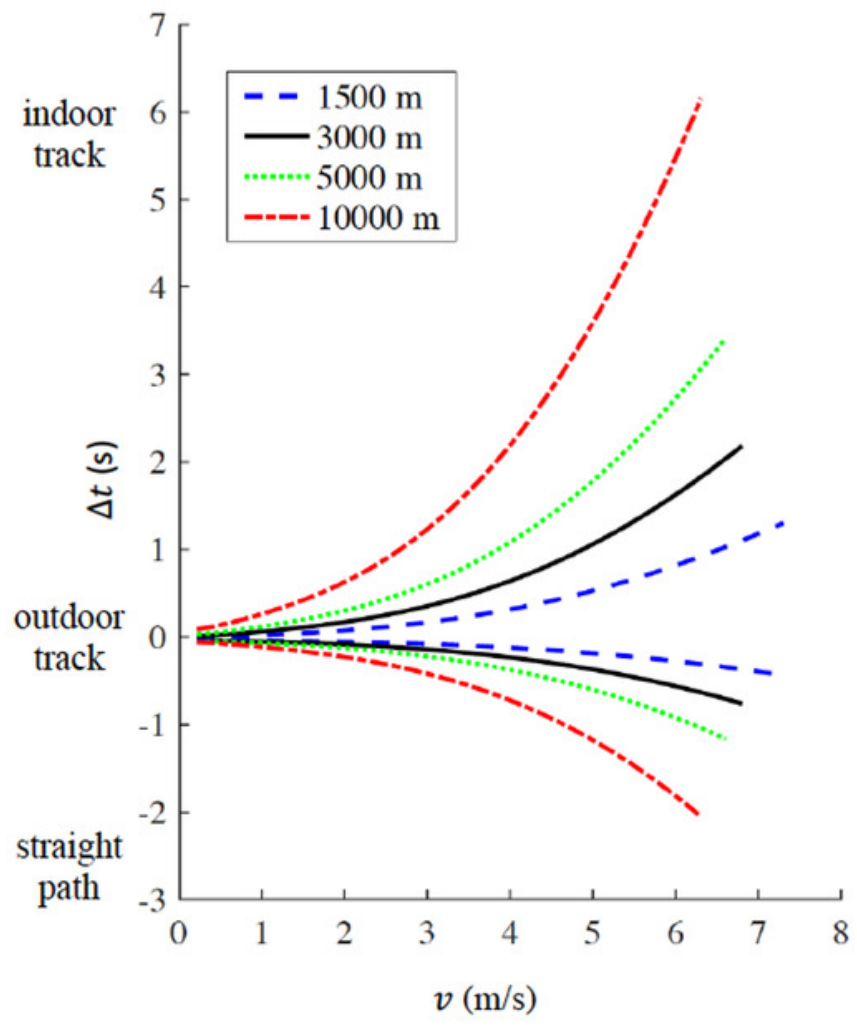

B

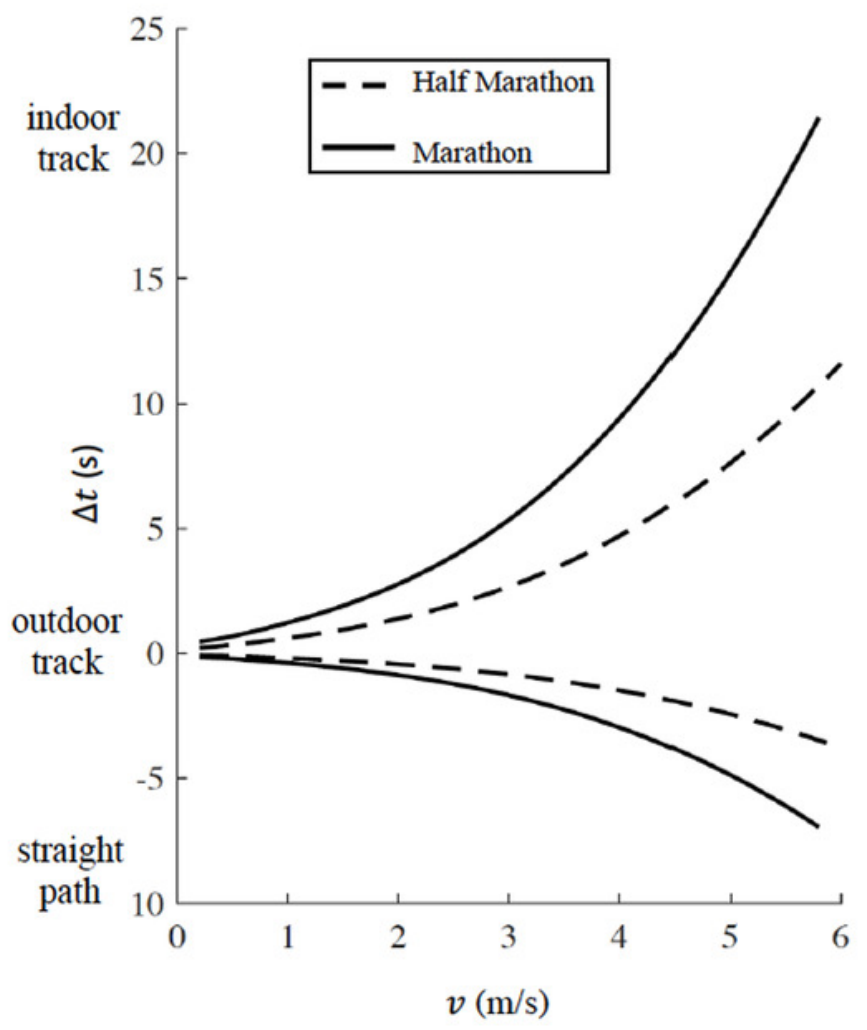




\section{Figure 5}

Time difference (delta t) for various racing distances $(1500 \mathrm{~m}, 3000 \mathrm{~m}, 5000 \mathrm{~m}$, and $10000 \mathrm{~m}$ ) as a function of radius ( $\mathrm{r}$ ) for tracks constrained to be $400 \mathrm{~m}$ lap distance.

When $r=36.8 \mathrm{~m}$, delta $\mathrm{t}=0 \mathrm{~s}$ corresponding to the respective world records on a standard 400 $\mathrm{m}$ outdoor track. delta $\mathrm{t}>0$ indicates that any radius $\mathrm{r}<36.8 \mathrm{~m}$ is detrimental for performance, while delta $t<0$ indicates that any radius $r>36.8 \mathrm{~m}$ favors performance. The ideal geometry for a $400 \mathrm{~m}$ track is a perfect circle with radius $r=63.66 \mathrm{~m}$. (Note: $r$ is the actual radius that includes the $0.3 \mathrm{~m}$ offset from the inner edge of the curb, to take in account the theoretical line of running according to IAAF rules (IAAF 2008b). 


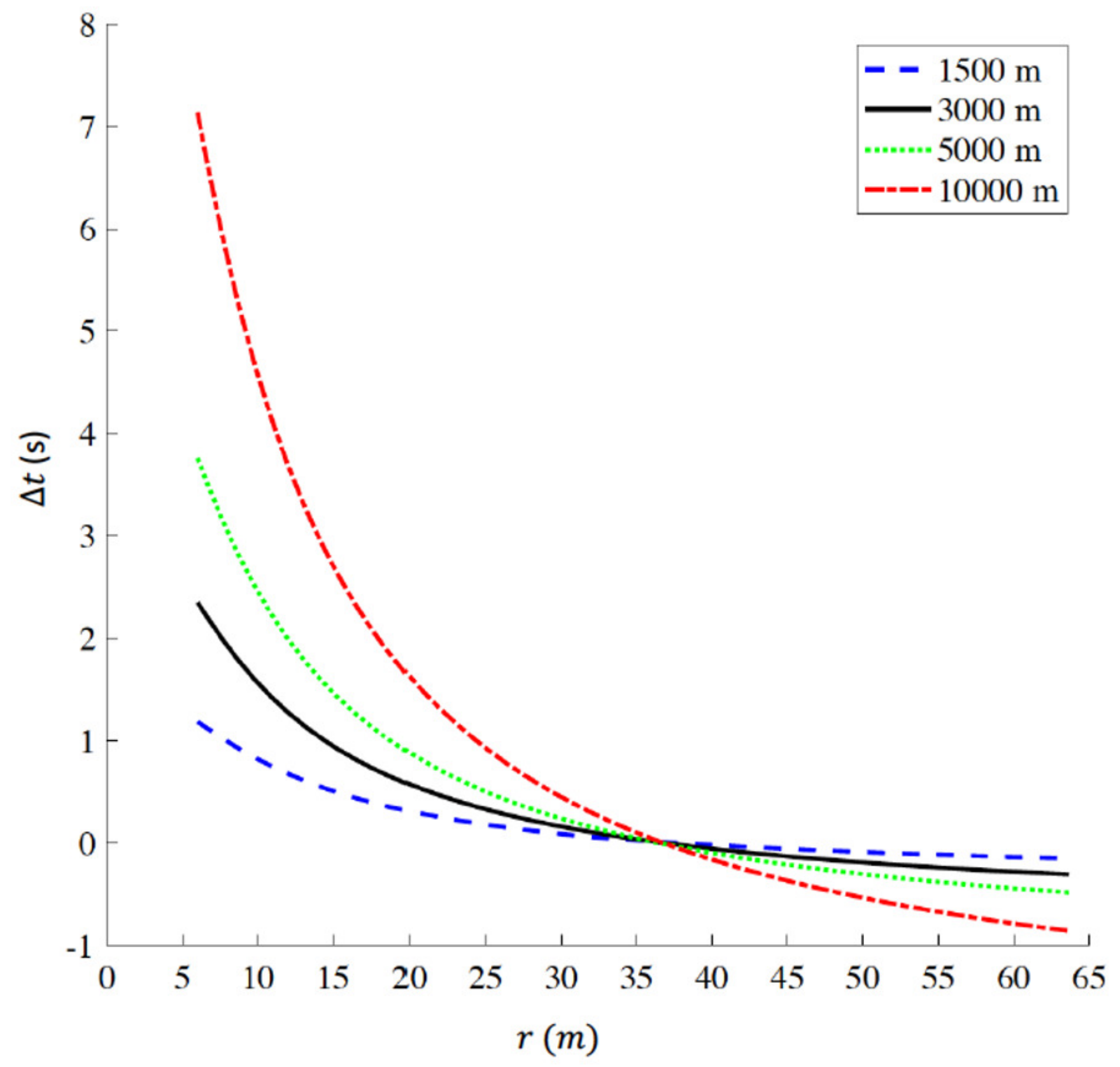

